\title{
Preparation and Application of Monoclonal Antibodies for a Sandwich Enzyme-Linked Immunosorbent Assay of the Major Soybean Allergen, Gly m Bd 30K
}

\author{
Hideaki TsuJI, Noriko BANDo, Masumi Kimoto, \\ Naoko OKADA, and Tadashi Ogawa \\ Department of Nutrition, School of Medicine, The University of Tokushima, \\ Tokushima 770, Japan
}

(Received April 24, 1993)

\begin{abstract}
Summary In order to obtain probes suitable for the determination of the major soybean allergen, Gly $m \mathrm{Bd} 30 \mathrm{~K}$, in soybean-related processed foods, we have prepared two monoclonal antibodies, F5 of IgG2a and H6 of IgM, by the fusion of P3U1 myeloma cells with the spleen cells of BALB/c mice immunized with the reductively carboxymethylated allergen (RCM-allergen). The two monoclonal antibodies were shown to be specific to the intact allergen as well as the RCM-allergen and to recognize distinct epitopes on the allergen. Of the monoclonal antibodies, F5 was conjugated with peroxidase. H6 and the labeled F5 were applied as the fixing antibody and the labeled first antibody, respectively, for a direct sandwich enzyme-linked immunosorbent assay of the allergen. When the allergen was extracted from the soybean-related foods with Tris- $\mathrm{HCl}$ buffer containing sodium dodecylsulfate and mercaptoethanol, the allergen, Gly $m$ Bd $30 \mathrm{~K}$, was shown to be measured in a range of 5-500 ng in this assay.
\end{abstract}

Key Words soybean, soybean allergen, 34-kDa oil-body-associated protein, monoclonal antibody

At present, food allergy is becoming a critical and social problem. Egg, milk, and soybean are known as representative foods eliciting the allergy. Among them, the soybean allergens have not been characterized. In the course of the investigations of the allergenicity of soybean, we have recently found about 15 allergenic proteins in soybean, which are specifically recognized by $\operatorname{lgE}$ antibodies in the sera of soybean-sensitive patients with atopic dermatitis (1). A major allergenic protein of soybean has been isolated and named as Gly $m$ Bd $30 \mathrm{~K}$. The allergen was demonstrated to be identical with the $34-\mathrm{kDa}$ oil body-associated protein of soybean (2), which had also been reported as a storage protein, p34, in the vacuoles of soybean by Herman and his colleagues (3-5). Interestingly, the allergen shares the highly homologous structure to one of the house dust mite allergens, Der $p \quad 1$, 
known as a papain-like thiol proteinase $(5,6)$.

Since the major allergen is shown not to be a component of $7 \mathrm{~S}$ - and 11 S-globulins, the major storage proteins of soybean, the allergenicity of soybean may be reduced by removal of these target allergens from the soybean using a food technological method or breeding one, so that hypoallergenic soybean products may be developed for soybean allergic patients. Processed foods in which soybean protein products are supplemented for processing aids have been increased, indicating that the processed foods may contain the major allergen, against which about two thirds of the soybean-sensitive patients with atopic dermatitis have specific IgE antibodies (1). Accordingly, the method to detect and determine the allergen in foods should be established in view of safety use of processed foods to allergic patients. We attempted to produce monoclonal antibodies (mAbs) against Gly $m$ $\mathrm{Bd} 30 \mathrm{~K}$, as probes for the assay system of the allergen in foods including soybean products.

In the present paper, we describe the preparation of two mAbs against the allergen and their application for a sandwich enzyme-linked immunosorbent assay (ELISA) of the allergen.

\section{MATERIALS AND METHODS}

Materials. The materials used in the present study were obtained from the sources indicated: mouse myeloma cell line, P3 $\times$ 63Ag8U1 (P3U1) (Shino Test Institute, Sagamihara, Japan), BALB/c mice (SLC, Shizuoka, Japan), complete and incomplete Freund's adjuvant (Nacalai Tesque, Kyoto, Japan), fetal bovine serum, sterilized L-glutamine and streptomycin-penicillin mixture (MA Bioproducts, CA, U.S.A.), RPMI 1640 (Nissui Pharmaceutical, Tokyo, Japan), a mouse monoclonal antibody isotyping kit (Amersham International PLC, Amersham, U. K.), aminopterin (Sigma, MO, U.S.A.), polyethylene glycol 4000 (Merck, Darmstadt, Germany), prepacked protein A column (Pierce Chemicals, IL, U.S.A.), nitrocellulose membrane (Bio-Rad, CA, U.S.A.), lysyl endopeptidase from Achromobacter lyticus M497-1 (Wako Pure Chemical Industries, Osaka, Japan), mouse lgG (Zymed Laboratories, CA, U.S.A.), peroxidase-conjugated sheep anti-mouse $\operatorname{lgG}$ and $\operatorname{lgM}$ (Organon Teknika, West Chester, PA, U.S.A.) and an electrophoresis calibrattion kit for molecular weight determination of low molecular weight proteins (Pharmacia, Uppsala, Sweden). Defatted soybean flakes and soybean seeds were prepared as described earlier (2). A mouse IgM monoclonal antibody against the whole cells of Strepotococcus porcinus ATCC 12391 used as a control was a gift of Drs. M. Yamato and F. Ohta (Department of Nutrition, School of Medicine, The University of Tokushima, Tokushima, Japan). Each fraction of soybean proteins was prepared in the same manner as desribed in a previous paper (7). The 7 S-globulin fraction obtained by the method of Thanh and Shibasaki (8) was used as the crude $7 \mathrm{~S}$-globulin fraction in this work. The crude $7 \mathrm{~S}$-globulin proteins were further fractionated by ultracentrifugation at $233,000 \times g$ for $20 \mathrm{~h}$ 
with a linear gradient of sucrose (10 to $30 \%)$ in $35 \mathrm{~mm}$ potassium phosphate buffer (pH 7.6) and this fraction is designated the purified 7 S-globulin fraction.

Preparation of the allergen. The purification of the allergen from defatted soybean flakes was done as described previously (2). Briefly, the allergen was isolated from defatted soybean flakes by Sepharose 6B chromatography and Con A affinity chromatography. The allergenic protein obtained by the above procedures was an oligomer. The oligomeric allergen was converted into the monomer by treatment with sodium dodecylsulfate (SDS) and mercaptoethanol, affer which the monomeric allergen was chromatographed on a Sephacryl S-200 column equilibrated with $100 \mathrm{~mm}$ sodium phosphate buffer ( $\mathrm{pH}$ 7.6) containing $1 \%$ SDS and $10 \mathrm{~mm}$ mercaptoethanol. The allergen obtained was reductively carboxymethylated with iodoacetate in order to avoid the polymerization of the monomeric allergenic protein. The reductively carboxymethylated allergen (RCM-allergen) was finally purified by HPLC on a column of DEAE-5PW $(7.5 \mathrm{~mm} \times 7.5 \mathrm{~cm}$, Tosoh, Tokyo, Japan). The allergen preparation obtained gave a single band on SDSpolyacrylamide gel electrophoresis (SDS-PAGE).

Preparation of $p 34$. The $34-\mathrm{kDa}$ oil-body-associated protein, $\mathrm{p} 34$, was prepared from the oil body pad of soybean by the method of Herman et al. (9). The purified protein was used as the intact allergen in this work.

Preparation of $m A$ bs. Female 8-week-old BALB/c mice were intraperitoneally injected with a mixture of the RCM-allergen $(50 \mu \mathrm{g} / \mathrm{mouse})$ and complete Freund's adjuvant. At the intervals of 3 weeks, the animals were intraperitoneally immunized two times with a mixture of the allergen $(50 \mu \mathrm{g} /$ mouse $)$ and incomplete Freund's adjuvant. Thereafter, the mice were intraperitoneally injected with the allergen $(50 \mu \mathrm{g} / \mathrm{mouse})$ in $10 \mathrm{~mm}$ sodium phosphate buffer ( $\mathrm{pH} 7.2)$ containing $0.15 \mathrm{M} \mathrm{NaCl}$ (PBS) as a final booster and killed 4 days later for the below-described fusion. The fusion of the immunized spleen cells and myeloma cells, P3U1, was done essentially in the same manner as described previously (10). For the preparation of the mAbs against the allergen produced by the hybridomas, the hybridoma cells were intraperitoneally injected into female BALB/c mice which had been primed with pristane 1 week before. After 10 to 14 days, ascitic fluids formed were collected. The mAbs in the ascites were fractionated with $\left(\mathrm{NH}_{4}\right)_{2} \mathrm{SO}_{4}$. An IgG mAb was further purified with a protein A column. An IgM mAb was used in the present study without further purification. Amounts of the mAbs were assayed by the method of Lowry et al. (11) using nonimmune mouse IgG as a standard.

Enzyme-linked immunosorbent assay (ELISA). Fifty microliters of the RCM-allergen $(50 \mu \mathrm{g} / \mathrm{ml})$ was added to the wells of a microplate. After incubation at $4^{\circ} \mathrm{C}$ overnight, the wells were blocked with $200 \mathrm{ml}$ of $1 \%$ bovine serum albumin (BSA) dissolved in PBS. The wells were washed three times with PBS containing $0.05 \%$ Tween 20 (PBS/Tween) and were incubated with culture supernatants or a $\mathrm{mAb}$. The wells were washed with PBS/Tween and mixed with peroxidaseconjugated sheep anti-mouse IgG or IgM, diluted $1: 2,000$ with PBS/Tween con- 
taining 1\% BSA. The immunocomplexes on the wells were incubated for $15 \mathrm{~min}$ at room temperature with $o$-phenylenediamine $(0.4 \mathrm{mg} / \mathrm{ml})$ and $0.01 \% \mathrm{H}_{2} \mathrm{O}_{2}$ as the substrates in $0.1 \mathrm{M}$ citrate $/ 0.1 \mathrm{M}$ phosphate buffer $(\mathrm{pH}$ 5.0) and absorbances of the reaction mixtures in the wells at $492 \mathrm{~nm}$ were determined with a microplate reader Model 450 (Bio-Rad, CA, U.S.A.).

Binding of the mAbs to the RCM-allergen immobilized on the wells of a microplate. Fifty microliters of the RCM-allergen $(30 \mu \mathrm{g} / \mathrm{ml})$ in PBS was added to the wells of a 96-well microplate and incubated at $4{ }^{\circ} \mathrm{C}$ overnight. After blocking with 1\% gelatin in PBS and washing with PBS/Tween, the protein on the well was mixed with varying concentrations of F5 or H6. The immunocomplexes were determined as described in ELISA. The peroxidase reaction was done at room temperature for $10 \mathrm{~min}$. The values obtained in the experiments without the $\mathrm{mAbs}$ were less than $4 \%$ of those in the presence of the mAbs. The values in the figures were calculated by correction with those obtained by the control experiments. The apparent dissociation constant values of the RCM-allergen and F5 or H6 were calculated from the double reciprocal plots of the absorbances at $492 \mathrm{~nm}$ and various concentrations of the mAbs.

Sandwich ELISA. Peroxidase-conjugated F5 used in a sandwich ELISA system of the allergen was prepared according to the method of Nakane and Kawaoi (12). Fifty microliters of $\mathrm{H} 6(50 \mu \mathrm{g} / \mathrm{ml})$ was added to wells of a 96-well microplate and incubated overnight at $4^{\circ} \mathrm{C}$. The wells were blocked with $1 \%$ gelatin in PBS at $37^{\circ} \mathrm{C}$ for $1 \mathrm{~h}$ and then washed three times with PBS/Tween. The $\mathrm{mAb}$ immobilized on the wells was reacted with varying amounts of the allergen at $37^{\circ} \mathrm{C}$ for $1 \mathrm{~h}$ and then with peroxidase-conjugated $\mathrm{F} 5$, the concentration of which was $1.4 \mu \mathrm{g} / \mathrm{ml}$. The immunocomplexes on the wells were determined as described above. The SDS/mercaptoethanol-denatured allergen used in the sandwich ELISA was prepared by dialysis of the intact allergen for $4 \mathrm{~h}$ against $50 \mathrm{~mm}$ Tris- $\mathrm{HCl}$ buffer (pH 8.0) containing 1\% SDS and $10 \mathrm{~mm}$ mercaptoethanol and then overnight against PBS.

SDS-PAGE. Proteins were mixed with the sample buffer (13) and heated in a boiling water bath for $5 \mathrm{~min}$. The samples were electrophoresed on $12 \%$ polyacrylamide gels according to the method of Laemmli (13). The proteins separated on the gels were stained with 0.1\% Coomassie Brilliant Blue R250 dissolveld in methanol/acetic acid/water $(5: 1: 4$, by vol.) and destained with methanol/acetic acid/water $(3: 1: 6$, by vol.)

Immunoblotting. Proteins were separated on $12 \%$ polyacrylamide gels as described above. The proteins on the gels were eiectrophoretically transferred onto nitrocellulose membranes. After blocking of the membranes with $1 \%$ BSA in $20 \mathrm{~mm}$ Tris- $\mathrm{HCl}$ buffer ( $\mathrm{pH} 7.4$ ) containing $0.15 \mathrm{M} \mathrm{NaCl}$ and $0.05 \%$ Tween 20 (buffer A), the membranes were incubated at $37^{\circ} \mathrm{C}$ for $1 \mathrm{~h}$ with a mAb against the allergen. As the control, nonimmune IgG was used instead of F5 and H6 was replaced by an IgM $\mathrm{mAb}$ against the bacterium. The bound $\mathrm{mAb}$ was reacted with peroxidase-conjugated sheep anti-mouse IgG or IgM, diluted $1: 2,000$ with buffer $\mathrm{A}$ 
containing 1\% BSA. The immunocomplexes on the membranes were detected by a 20-min incubation at room temperature with 4-chloro-1-naphthol $(0.3 \mathrm{mg} / \mathrm{ml})$ and $0.03 \% \mathrm{H}_{2} \mathrm{O}_{2}$ as the substrates in $50 \mathrm{mM}$ Tris- $\mathrm{HCl}$ buffer $(\mathrm{pH} \mathrm{7.3)}$. The immunoblotting of the proteolytic products derived from the intact allergen with lysyl endopeptidase was done as follows. The intact allergen $(40 \mu \mathrm{g})$ was digested at $37^{\circ} \mathrm{C}$ with lysyl endopeptidase (1:200 lysyl endopeptidase to the allergen, weight ratio) as described in a previous paper (14). After a 5-min incubation, the mixture was mixed with an equal volume of the sample buffer and heated for $5 \mathrm{~min}$ in a boiling water bath. The samples prepared were applied on the lanes of a $17 \%$ polyacrylamide gel. Affer SDS-PAGE, the peptides separated on the gel were electrophoretically transferred onto a nitrocellulose membrane and immunoblotted with F5 and H6 in the same manner as described above.

\section{RESULTS AND DISCUSSION}

\section{Preparation of $m A b s$}

When female BALB/c mice were injected with the intact allergen as antigen, antisera of high antibody titer could not be obtained. In contrast, BALB/c mice intraperitoneally immunized with the $\mathrm{RCM}$-allergen produced antisera of high antibody titer against the RCM-allergen. Therefore, in the present study, the RCM-allergen was used as the immunogen. The spleen cells of an immunized mouse were fused with P3U1 myeloma cells. Finally, two hybridoma cell lines producing mAbs against the allergen have been established by two fusions. The two mAbs produced by the hybridomas are named F5 and H6 in this paper. The class and subclass of the mAbs were examined using a mouse monoclonal antibody isotyping kit. The light chains of both mAbs were $\kappa$. The heavy chains of F5 were $\gamma 2 \mathrm{a}(\mathrm{IgG})$ and those of $\mathrm{H} 6$ were $\mu(\operatorname{IgM})$.

\section{Properties of $m A b s$}

As shown in Fig. 1, F5 and H6 bound to the SDS-denatured RCM-allergen, indicating that the two mAbs recognize sequential epitope(s) on the RCM-allergen. Both of the mAbs were shown to bind to the intact allergen. The apparent dissociation constant values of $\mathrm{F} 5$ and $\mathrm{H} 6$ for the binding to the RCM-allergen immobilized on a microplate were $2.3 \times 10^{-9}$ and $1.3 \times 10^{-8} \mathrm{M}$, respectively (Fig. 2). Also, the intact allergen bound to the mAbs with about one fifth of the binding constants for the RCM-allergen (data not shown). These findings indicate that the decarboxymethylation of the RMC-allergen does not interfere essentially with the immunoreaction of the mAbs with the RCM-allergen, although it decreases the affinity of the mAbs for the RCM-allergen.

In order to examine whether the two mAbs bind to the same epitope on the allergen, we digested the intact allergen with lysyl endopeptidase as decribed in a previous paper (14). The proteolytic products were immunoblotted with the mAbs (Fig. 3). F5 immunoblotted 27-, 22.5-, 17.5-, 14-, and 13.5-kDa peptides in 


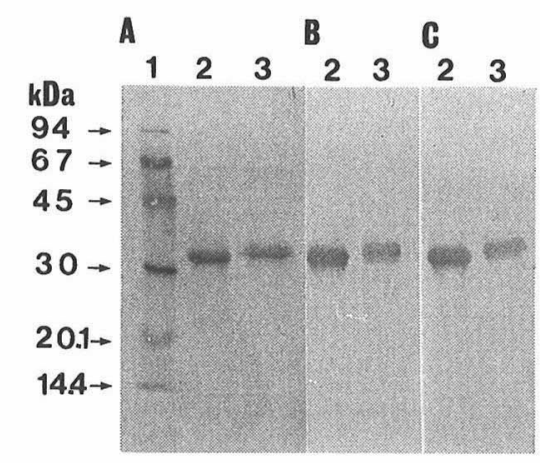

Fig. 1. Immunoblots of the intact allergen and the RCM-allergen with F5 (B) and H6 (C). After SDS-PAGE, the proteins were electrophoretically transferred onto nitrocellulose membranes. The proteins on the membranes were immunoblotted with F5 $(1 \mu \mathrm{g} / \mathrm{ml})$ or $\mathrm{H} 6(3 \mu \mathrm{g} / \mathrm{ml})$. A: The proteins stained with Amido Black 10B. B: The proteins immunoblotted with F5. C: The proteins immunoblotted with H6. 1, standard proteins; 2, the intact allergen; 3, the RCM-allergen. The standard proteins used were as follows: phosphorylase $\mathrm{b}$ $(94 \mathrm{kDa})$, bovine serum albumin $(67 \mathrm{kDa})$, ovalbumin $(45 \mathrm{kDa})$, carbonic anhydrase $(30 \mathrm{kDa})$, soybean trypsin inhibitor $(20.1 \mathrm{kDa})$, and $\alpha$-lactoglobulin $(14.4 \mathrm{kDa})$.
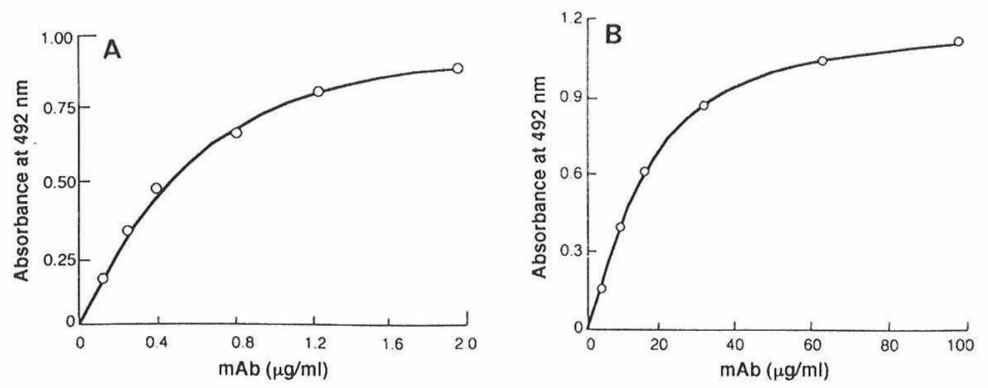

Fig. 2. Binding of F5 (A) and H6 (B) to the RCM-allergen immobilized on the wells of a microplate.

addition to the $34-\mathrm{kDa}$ allergen, but $\mathrm{H} 6$ bound to only $27-\mathrm{kDa}$ peptide besides the 34-kDa allergen. These results show that the two mAbs recognize distinct epitopes on the allergen. This finding indicates that both of the mAbs can be used as two antigen-binding antibodies in a sandwich ELISA system of the allergen.

We further investigated whether the present $\mathrm{mAbs}$ are specific for the allergen of soybean proteins. In the immunoblotting analyses of the whole extract and the crude 7 S-globulin proteins of soybean with F5, only one intense band corresponding to the allergen with a molecular mass of $34 \mathrm{kDa}$ was observed (Fig. 4B). A faint 34-kDa peptide band was also shown in the immunoblots obtained with the 


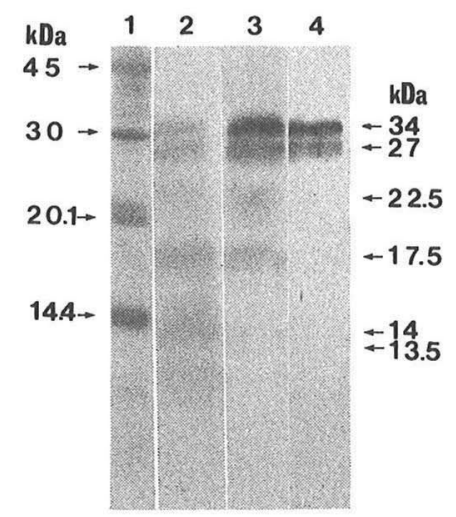

Fig. 3. Immunoblotting patterns of the proteolytic products derived from the intact allergen with lysyl endopeptidase. 1, standard proteins; 2, the peptides stained with Amido Black 10B; 3 and 4, peptides immunoblotted with F5 and H6, respectively.

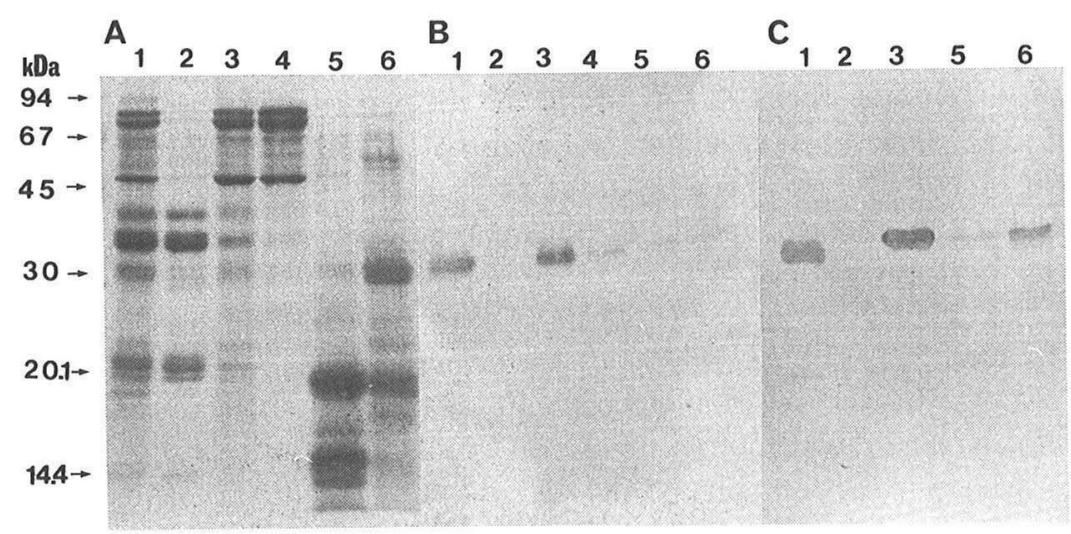

Fig. 4. Immunoblotting analyses of the fractions of soybean proteins with F5 (B) and $\mathrm{H} 6(\mathrm{C})$. A: The proteins stained with Amido Black 10B. B and C: The proteins immunoblotted with $\mathrm{F} 5$ and $\mathrm{H} 6$, respectively. 1, whole extract; 2, $11 \mathrm{~S}$-globulin fraction; 3, crude $7 \mathrm{~S}$-globulin fraction; 4, purified $7 \mathrm{~S}$-globulin fraction; 5, 2 S-globulin fraction; 6, whey fraction.

$\mathrm{mAb}$ of the whey and purified $7 \mathrm{~S}$-globulin proteins. These results indicate that the allergen occurs mainly in the crude $7 \mathrm{~S}$-globulin fraction, and that the allergenic protein is not completely removed during the preparation of the latter two fractions. H6 showed essentially the same immunoblotting pattern of each fraction of soybean proteins as those obtained with F5 (Fig. 4C). These findings demonstrate that both the mAbs recognize only the allergen of soybean proteins.

The above observations show that the two mAbs prepared can act as very 


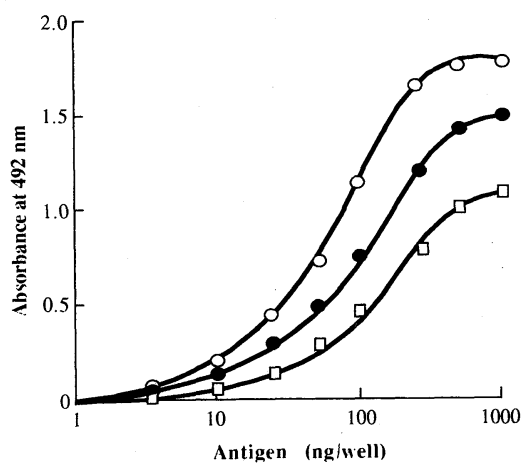

Fig. 5. Dose response curves for the RCM-allergen, the intact allergen, and the SDS/mercaptoethanol-denatured allergen in the sandwich ELISA. The sandwich ELISA was done as described in the text. $\bigcirc$, the RCM-allergen; $\bullet$, the SDS/mercaptoethanol-denatured allergen; $\square$, the intact allergen.

useful probes in a sandwich ELISA system of the allergen. Therefore, we tried to develop a sandwich ELISA of the allergen using the two mAbs. In preliminary experiments concerning the extraction of the allergen from various soybean products, $50 \mathrm{~mm}$ Tris- $\mathrm{HCl}(\mathrm{pH} 8.0)$ containing 1\% SDS and $10 \mathrm{~mm}$ mercaptoethanol (SDS/mercaptoethanol) was shown to be an excellent buffer for the efficient extraction of the allergen from the products. In the present study, the RCMallergen, the intact allergen, and the SDS/mercaptoethanol-denatured allergen were assayed by the sandwich ELISA (Fig. 5). The sensitivity of the assay system to the antigens was in a decreasing order: the RCM-allergen $>$ the SDS/mercaptoethanoldenatured allergen $>$ the intact allergen. The detectable ranges of the assay system were 2-200 ng for the RCM-allergen, 5-500 ng for the SDS/mercaptoethanoldenatured allergen, and 10-500 ng for the intact allergen. These results show that the assay system is very sensitive to the SDS/mercaptoethanol-denatured allergen. As described above, the allergen can efficiently be extracted from soybean-related foods with SDS/mercaptoethanol. Thus, the above findings demonstrate that the assay system developed by the present study can excellently measure the allergen in foods including soybean products. The analysis of the allergen in foodstuffs is in progress using the present sandwich ELISA. The results as to the distribution of the allergen in foodstuffs will be described elsewhere.

\section{REFERENCES}

1) Ogawa, T., Bando, N., Tsuji, H., Okajima, H., Nishikawa, K., and Sasaoka, K. (1991): Investigation of the IgE-binding proteins in soybeans in immunoblotting with the sera of the soybean-sensitive patients with atopic dermatitis. J. Nutr. Sci. Vitaminol., 37, $555-565$.

2) Ogawa, T., Tsuji, H., Bando, N., Kitamura, K, Zhn, Y.-L., Hirano, H., and Nishi- 
kawa, K. (1993): Identification of the soybean allergenic protein, Gly $m$ Bd $30 \mathrm{~K}$, with the soybean seed 34-kDa oil-body-associated protein. Biosci. Biotech. Biochem., 57, 1030-1033.

3) Herman, E. M. (1987): Immunogold-localization and synthesis of an oil-body membrane protein in developing soybean seed. Planta, 172, 336-345.

4) Herman, E. M., Melroy, D. L., and Buckhout, T. J. (1990): Apparent processing of a soybean oil body protein accompanies the onset of oil mobilization. Plant Physiol., 94, 341-349.

5) Kalinski, A., Weisemann, J. M., Matthews, B. F., and Herman, E. M. (1990): Molecular cloning of a protein associated with soybean seed oil-bodies that is similar to thiol proteases of the papain family. J. Biol. Chem., 265, 13843-13848.

6) Cua, K. Y., Stewart, G. A., Thomas, W. R., Simpson, R. J., Dilworth, R. J., Plozza, T. M., and Turner, K. J. (1988): Sequence analysis of cDNA coding for a major house dust mite allergen, Der $p$ 1. Homology with cysteine proteases. J. Exp. Med., 167, 175-182.

7) Ogawa, T., Tsuji, H., Bando, N., and Sasaoka, K. (1992): Identification of a soybean protein producing IgE antibodies in BALB/c mice. Biosci. Biotech. Biochem., 56, 978979.

8) Thanh, V. H., and Shibasaki, M. (1976): Major proteins of soybean seeds. A straightforward fractionation and their characterization. J. Agric. Food Chem., 24, 1117-1121.

9) Kalinski, A., Melroy, D. L., Dwivedi, R. S., and Herman, E. M. (1992): A soybean vacuolar protein (P34) related to thiol proteases is synthesized as a glycoprotein precursor during seed maturation. J. Biol. Chem., 267, 12068-12076.

10) Tsuji, H., Ogawa, T., Bando, N., Kimoto, M., and Sasaoka, K. (1990): A monoclonal antibody recognizing the FAD-binding site of 4-aminobenzoate hydroxylase from Agaricus bisporus. J. Biol. Chem., 265, 16064-16067.

11) Lowry, O. H., Rosebrough, N. J., Farr, A. L., and Randall, R. J. (1951): Protein measurement with Folin phenol reagent. J. Biol. Chem., 193, 265-275.

12) Nakane, P. K., and Kawaoi, A. (1974): Peroxidase-labeled antibody. A new method of conjugation. J. Histochem. Cytochem., 22, 1084-1091.

13) Laemmli, U. K. (1970): Cleavage of structural proteins during the assembly of the head of the bacteriophage T4. Nature, 227, 680-685.

14) Ogawa, T., Tsuji, H., Kimoto, M., and Sasaoka, K. (1992): Preparation and characterization of monoclonal antibodies against 4-aminobenzoate hydroxylase from Agaricus bisporus. Biochim. Biophys. Acta, 1115, 220-224. 